\title{
Instructional Programme on Experiential Learning in Science Education: Appraising its Impact through Students' Reflections
}

\author{
Sreetanuka Nath \\ K. J. Somaiya Comprehensive College of Education, Training and Research, India
}

\begin{abstract}
Childhood is a period of growth and change, involving developing one's physical and mental capacities to the fullest. There is a constant need to recognize the child as a natural learner, and knowledge as the outcome of the child's own activity. In everyday lives, one can enjoy the curiosity, inventiveness and constant querying of children. They actively engage with the world around them, exploring, responding, inventing and working things out, and making meanings. This study entails to find the effect of developed Instructional Program on Experiential Learning in Science on change in preference about students' interest or what they would like to learn. Results indicate change in interest on certain items based on motivation achieved due to implementation of the instructional program. It also studies the impact of the Instructional Programme on Experiential Learning in Science Education on the reflective thinking process of the secondary school students
\end{abstract}

\section{Introduction}

National Curriculum Framework [1] lays emphasis on 'child centered' approach giving primacy to children's experiences, their voices, and their active participation. The key points are as under: -

- Learners actively construct their own knowledge by connecting new ideas to existing ideas on the basis of materials/ activities presented to them (experience).

- The structuring and restructuring of ideas are essential features as the learners' progress in learning.

- The engagement of learners, through relevant activities, can further facilitate in the construction of mental images of the relationships (cause-effect).

Formalization of the theory of constructivism is generally attributed to Jean Piaget [2], who articulated mechanisms by which knowledge is internalized by learners. He suggested that through processes of accommodation and assimilation, individuals construct new knowledge from their experiences.
Activity based teaching methods are based on the constructivist learning theory. Constructivists suggest learning is more effective when a student is actively engaged in the construction of knowledge rather than passively receiving it. According to Bruner [3] children learn through a process of inquiry in which they discover relationships between concepts. As the learner is faced with problems he or she uses their prior knowledge, experiences, and selfmotivation to uncover new truths. By physically interacting with concepts through questioning, experimenting, and researching students become part of the findings and are more inclined to comprehend the relationships between the hypotheses.

According to Audrey Gray [4] the characteristics of an activity based classroom are:

- The learners are actively involved and the environment is democratic.

- The activities are interactive and studentcentered

- The teacher facilitates a process of learning in which students are encouraged to be responsible and autonomous

Vygotsky [5] highlighted the convergence of the social and practical elements in learning by saying that the most significant moment in the course of intellectual development occurs when speech and practical activity, two previously completely independent lines of development, converge. Through practical activity a child constructs meaning on an intrapersonal level, while speech connects this meaning with the interpersonal world shared by the child and her/his culture.

According to Rousseau [6], activity based method is one of the most psychologically satisfying learning experience for the child. It is a democratize way of teaching where the student learn to respect each other's view points and develop a sense of selfworth.

Zemelman, Daniels, and Hyde [7] tell us that learning in all subject areas involves inventing and constructing new ideas. They suggest that constructivist theory be incorporated into the curriculum, and advocate that teachers create environments in which children can construct their own understanding.

By engaging in formal, guided, authentic, realworld experiences, individuals: 
- deepen their knowledge through repeatedly acting and then reflecting on this action,

- develop skills through practice and reflection,

- support the construction of new understandings when placed in novel situations, and

- extend their learning as they bring their learning back to the classroom [8].

These experiences lay the tombstone towards conceptual development which keeps on updating with time and brings about experiential learning.

Experiential learning theory defines learning as "the process whereby knowledge is created through the transformation of experience. Knowledge results from the combination of grasping and transforming experience" [9].Experiential learning is any learning that supports students in applying their knowledge and conceptual understanding to real-world problems or situations where the instructor directs and facilitates learning. The classroom, laboratory or the community can serve as a setting for experiential learning through embedded activities such as case and problem-based studies, guided inquiry, simulations, experiments, or art projects [10].

"An emerging trend in science educator professional development is experiential learning through what can best be described as immersive and extraordinary informal experiences. Examples include fieldwork with scientists, experience in research labs, and STEM-oriented exploration, travel, and adventure. Experientially based learning strategies in general have a long history rooted in the early work of John Dewey (1938)[29], and later evolved in work by Piaget [2], Kurt Hahn (1957)[30], Paulo Freire (1970) [31], Vygotsky [5], Kolb [9] and many others. Experiential education is best understood as a philosophy of education, in contrast to learning methodologies such as didactic or rote learning that are mostly concerned with knowledge delivery. In contrast, experiential education is concerned with learning from direct first-person experience and a holistic perspective that goes beyond content to include the construction of knowledge, attitudes, beliefs, and transfer of learning. It in describes experiential education as a process where "Learners are engaged intellectually, emotionally, socially, politically, spiritually, and physically in an uncertain environment where the learner may experience success, failure, adventure, and risk taking". Quay asserts that learning through experience occurs at the level of the individual (constructivism), the small group (social constructionism), and culture (cultural discourses) [11].

Original research done by Edgar Dale [12], shows that the effectiveness of learning or the learning retention rate based on the learning experiences while doing the real thing or simulating the real experience is high $(90 \%)$ compared to other teaching methods like reading, hearing (knowledge retention 10\%), seeing audio/visual video (knowledge retention 30\%).

Experiential Learning Cycles (ELC) is models for understanding how the process of learning works. They are distinct from other models of learning such as behavioral models or social learning models. Experiential Learning Cycles treat the learners' subjective experience as of critical importance in the learning process. ELC propose an interactive series of process which underlies learning. ELC are commonly used to help structure experience-based learning. The underlying philosophy of ELC is that people learn experientially and that some experiences are educative while others are miseducative. It is the teachers' responsibility to structure and organize a series of experiences which positively influence individuals' future experiences [13].

The Experiential Learning Cycle models commonly in Experiential Learning literature have been identified and can be organized in terms of the number of stages they propose.

Looking at the prospect of experiential learning and its effectiveness the researcher decided to find its effect on change in preference about students' interest or what they would like to learn. The second model (experience-reflection) was followed in this study. The second model, a 2-stage model (experience-reflection), is that experiences followed by periods of reflection are an effective way to structure and facilitate experiential education which is explained by James [14], Bacon [15] and Neill [16]. The researcher devised an Instructional Programme on Experiential Learning in Science Education for secondary school students for the purpose.

"For a successful experiential learning endeavor a holistic approach follows from the perception that metacognition and construction of meaning are intertwined. Metacognition refers to a person's knowledge of the nature of learning, effective learning strategies, and his/her own learning strengths and weaknesses; awareness of the nature and progress of the current learning task (i.e., what you are doing and why you are doing it); and control over learning through informed and purposeful decision making. Early studies attempted to promote metacognition in reading. Later ones showed that metacognition could be achieved in science classrooms, and resulted in improved cognitive and affective outcomes. Better metacognition, however, did not occur easily. Students and their teacher all had to expend time and effort on personal intellectual development. They needed support from the researcher to maintain their effort and to reach their goal." [17].

"The meaning that any learner derives from a lesson depends on a number of factors: the person's 
attitudinal state; perception of the nature, purpose and progress of the lesson; existing knowledge; and decisions about what to do as learning proceeds. Attitudes, abilities, and knowledge are all involved in the processing of information. To attend to only one of these aspects would be to cripple the study." [17].

Constructivism complements metacognition in effecting personal change. Adequate metacognition empowers the learner to undertake the constructivist processes of recognition, evaluation, and revision of personal views. Hence it can be inferred that one reason for the lack of success in attempts to bring out conceptual change is that the strategies paid insufficient attention to assisting the learners to become sufficiently metacognitive for them to control the nature and direction of change [17].

The studies of metacognition and conceptual change, and the insights from the Project for Enhancing Effective Learning, led us to adopt an integrative perspective on change. The perspective includes a holistic approach to the study of individuals, research based on personal and professional reflection, and convergence of process and outcomes in teaching and learning.

Critical thinking is used to describe the use of those cognitive skills or strategies that increase the "probability of a desirable outcome...thinking that is purposeful, reasoned, and goal directed - the kind of thinking involved in solving problems, formulating inferences, calculating likelihoods, and making decisions when the thinker is using skills that are thoughtful and effective for the particular context and type of thinking task" [18].

"Reflective thinking, on the other hand, is a part of the critical-thinking process that refers specifically to the processes of analyzing and making judgments about what has happened. Dewey (1933) [28] suggests that reflective thinking is an active, persistent, and careful consideration of a belief or supposed form of knowledge, the grounds that support that knowledge, and the further conclusions to which that knowledge leads. Learners are aware of and control their learning by actively participating in reflective thinking - assessing what they know, what they need to know, and how they bridge that gap during learning situations." [19].

The National Science Education Standards state that teachers of science, at all levels, must make decisions "such as when to change the direction of a discussion, how to engage a particular student, [and] when to let a student pursue a particular interest" [20].

"Teachers struggle to decide when to guide students toward a specific outcome and when to allow them to set their own goals. Because students think about what they are learning, reflection is a way for students to set their own goals as well as guide their own learning." [19].
The decision to use reflection in the science classroom is one that requires prior planning and thought. In the present study reflection of students regarding the experiential learning programme served as a clue towards acceptability of the said programme.

\section{Objectives of the Study}

- To develop Instructional Programme on Experiential Learning in Science Education for secondary school students.

- To study the effect of developed Instructional Program in Science on change in preference about students' interest or what they would like to learn.

- To study the impact of the Instructional Programme on Experiential Learning in Science Education on the reflective thinking process of the secondary school students

\section{Research Questions}

- What is the effect of developed Instructional Programme on Experiential Learning in Science Education on change in preference about students' interest or what they would like to learn?

- What is the impact of the Instructional Programme on Experiential Learning in Science Education on the reflective thinking process of the secondary school students?

\section{Methodology and Design of the Study}

For the present study the researcher has selected the Experimental Method by keeping in mind the objectives of the study and the problem. The researcher has used Quasi experimental research design involving Pretest-Posttest non-Equivalent Groups Design. The pre-tests was administered before the application of the experimental and control treatments and post-tests at the end of the treatment period. Pre-test scores were used in analysis of covariance to statistically control for any differences between the groups at the beginning of the study.

$\mathrm{Z}$ test was used for the present study. Since in the present study students merely had to tick the items only percentages and the $\mathrm{z}$ test of probabilities were possible.

During the intervention, reflections of the learners were taken through question answer sessions, interviews and discussions. 


\section{Tools of the Study}

One item ('Science: - Things to learn about')from standardised tool 'Students idea about science and scientists' by SveinSjøberg from Norway, Jane Mulemwa from Uganda and Jayshree Mehta from India [21] was taken for the study.

Various types of reflection tools are available like Directed Writings, The Critical Incident, DoubleEntry Journal. Various group exercises are also available as reflection tool like, Structured Class Discussions, Dialogue, Community Mural, Taking Sides. Various activities also can be conducted as reflection tool like, What Is This, Truth Is Stranger than Fiction, Values Continuum [22]. For the present study Double-Entry Journal was used to note the reflections of students during the implementation of the Instructional Programme on Experiential Learning in Science Education.

When using a double-entry journal, students write one-page entries each week: Students describe their personal thoughts and reactions to the service experience on the left page of the journal, and write about key issues from class discussions or readings on the right page of the journal. Students then draw arrows indicating relationships between their personal experiences and course content. This type of journal is a compilation of personal data and a summary of course content to help them make the connections.

\section{Sample of the Study}

Sample for the present study includes 80 students of secondary school (CBSE Board) from class IX of two schools in Mumbai, Maharashtra. 40 students formed the experimental group and 40 formed control group.

\section{Analysis and Discussion}

Students were presented with a large list of (69) topics and asked if they would like to learn more about these topics. The aim of the exercise was to learn about what are the topics that students are more interested in, and would like specifically to have in their school syllabi. Since, they merely had to tick the items only percentages were possible and the $\mathrm{z}$ test of probabilities [23]. The topic with their $\mathrm{z}$ values are given in the Table 1 .
Students were enthusiastic in ticking the categories in which they were interested in. Some of the categories which had significant $\mathrm{z}$ value for the experimental group students post intervention were; Why birds and planes can fly $(z=3.45, p=0.01)$, How birds/animals communicate $(z=3.76, p=0.01)$, How birds and fish find way home $(z=3.09, p=0.01)$, Plants/animals elsewhere $(z=3.09 p=0.01)$, How the body is built and functions $(\mathrm{z}=3.02 \mathrm{p}=0.01)$, Bacteria, viruses and diseases $(\mathrm{z}=3.04, \mathrm{p}=0.01$, Vaccination and prevention $(\mathrm{z}=2.76, \mathrm{p}=0.01)$, What we should eat to be healthy $(z=3.11, p=0.01)$, How babies are made and grow $(\mathrm{z}=2.87 \mathrm{p}=0.01)$, Detergents, soaps and how they work $(\mathrm{z}=3.12, \mathrm{p}=$ $0.01)$, How the eye can $\operatorname{see}(\mathrm{z}=3.01, \mathrm{p}=0.01)$, Colours and how we see them $(z=2.76, p=0.01)$, Acoustics and sound $(\mathrm{z}=3.13, \mathrm{p}=0.01)$, How the car can hear $(z=2.97, p=0.01)$, Music, instruments and sounds $(Z=3.54, p=0.01)$, What is the rainbow/ why you see it $(z=2.76, p=0.01)$, Why the sky is blue/stars twinkle $(\mathrm{z}=4.65, \mathrm{p}=0.01)$, the greenhouse effect $(\mathrm{z}=2.79, \mathrm{p}=0.01)$, The moon, the stars and planets $(z=3.98 \mathrm{p}=0.01)$, Rockets and space travel $(z=3.09 p=0.01)$, Possibility of life outside earth $(z=3.05, p=0.01)$, Electricity, produced and used at home $(\mathrm{z}=3.35, \mathrm{p}=0.01)$, How to get clean/safe drinking water $(\mathrm{z}=2.94 \mathrm{p}=0.01)$, Children in other parts of the world $(z=2.98, p=0.01)$, How scientists think and work $(\mathrm{z}=2.79 \mathrm{p}=0.01)$, Famous scientists and their lives $(\mathrm{z}=2.88, \mathrm{p}=0.01)$, Important inventions and discoveries $(\mathrm{z}=2.97 \mathrm{p}=0.01)$, How nuclear power plant functions $(\mathrm{z}=3.24 \mathrm{p}=0.01)$, What an atomic bomb consist of $(\mathrm{z}=3.64 \mathrm{p}=0.01)$.

A look at the control group pre-test and post-test figures shows increment in the interest towards the things they would like to learn only in very few aspects. The fact is that during face to face teaching through lecture method, the students are not exposed to the activities which could enhance their skill aspect.

Since the second model (experience-reflection) was followed in this study, there were periods of reflection after each activity. When using a doubleentry journal, students write one-page entries during conduct of each activity: Students describe their personal thoughts and reactions to the service experience on the left page of the journal, and write about key issues from class discussions or readings on the right page of the journal. To structure the reflective process, questions were put in the reflective sheet. 
Table 1. Z values of 'Science: - Things to learn about' for Experimental and Control Groups

\begin{tabular}{|c|c|c|c|c|c|c|c|c|}
\hline \multirow[t]{2}{*}{ Things to learn } & \multicolumn{4}{|c|}{ Experimental group } & \multicolumn{4}{|c|}{ Control group } \\
\hline & $\underbrace{\frac{\tilde{g}}{d}}_{0}$ & 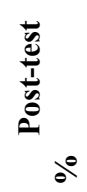 & 0 & $\mathbf{Z}$ & $\begin{array}{l}00 \\
\overline{0} \\
\frac{0}{0} \\
\frac{0}{2} \\
0\end{array}$ & 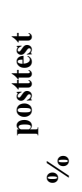 & 0 & $\mathbf{Z}$ \\
\hline The car and how it works & 55 & 64 & 9 & 1.45 & 54 & 53 & -1 & -0.75 \\
\hline Pollution and dangers of traffic & 56 & 61 & 5 & 1.53 & 60 & 56 & -4 & -1.42 \\
\hline Why birds and planes can fly & 62 & 88 & 26 & 3.45 & 53 & 52 & -1 & -1 \\
\hline How birds/animals communicate & 66 & 80 & 14 & 3.76 & 60 & 63 & 3 & 0.78 \\
\hline How birds and fish find way home. & 56 & 77 & 21 & 3.09 & 59 & 56 & -3 & -0.55 \\
\hline Plants/animals in the neighbourhood & 57 & 65 & 8 & 0.64 & 55 & 65 & 10 & 1.95 \\
\hline Plants/animals elsewhere & 46 & 66 & 20 & 3.09 & 56 & 53 & -3 & -0.88 \\
\hline How the body is built and functions & 50 & 54 & 4 & 3.02 & 45 & 47 & 2 & 0.61 \\
\hline Bacteria, viruses and diseases & 78 & 86 & 8 & 3.04 & 72 & 71 & -1 & -0.39 \\
\hline Vaccination and prevention & 76 & 88 & 12 & 2.76 & 78 & 76 & -2 & -0.95 \\
\hline AIDS & 74 & 81 & 7 & 1.02 & 70 & 69 & -1 & -0.67 \\
\hline How plants grow and their needs & 55 & 54 & -1 & 1.23 & 64 & 64 & 0 & 0.19 \\
\hline How to eat/cook food the best way & 83 & 90 & 7 & 1.43 & 74 & 75 & 1 & 0.69 \\
\hline What we should eat to be healthy & 76 & 86 & 10 & 3.11 & 56 & 54 & -2 & -0.87 \\
\hline How babies are made and grow & 66 & 88 & 22 & 2.87 & 64 & 63 & -1 & -0.34 \\
\hline Detergents, soaps and how they work & 61 & 83 & 22 & 3.12 & 55 & 56 & 1 & 0.95 \\
\hline Evolution of life on earth & 61 & 67 & 6 & 1.21 & 60 & 62 & 2 & 0.65 \\
\hline Dinosaurs & 70 & 72 & 2 & 1.02 & 67 & 65 & -2 & -0.24 \\
\hline Origin and evolution of humans & 75 & 84 & 9 & 0.97 & 80 & 75 & -5 & -0.67 \\
\hline Plants and animals inter-dependence & 53 & 63 & 10 & 0.82 & 54 & 53 & -1 & -0.32 \\
\hline Light and optics & 43 & 54 & 11 & 0.43 & 52 & 56 & 4 & 1.03 \\
\hline How the eye can see & 84 & 92 & 8 & 3.01 & 78 & 75 & -3 & -0.32 \\
\hline Colours and how we see them & 43 & 58 & 15 & 2.76 & 47 & 49 & 2 & 1.05 \\
\hline Acoustics and sound & 67 & 94 & 27 & 3.13 & 56 & 55 & -1 & -0.67 \\
\hline How animals and plants use colours & 68 & 67 & -1 & 0.34 & 65 & 68 & 3 & 0.95 \\
\hline How the car can hear & 67 & 78 & 11 & 2.97 & 64 & 63 & -1 & -0.64 \\
\hline Music, instruments and sounds & 67 & 89 & 22 & 3.54 & 78 & 77 & -1 & -0.74 \\
\hline Sound and music of birds and animals & 63 & 70 & 7 & 1.32 & 62 & 64 & 2 & 1.06 \\
\hline Earthquakes and volcanoes & 56 & 65 & 9 & 1.98 & 59 & 55 & -4 & -0.88 \\
\hline Lightning and thunder & 55 & 50 & -5 & 0.21 & 58 & 56 & -2 & -0.25 \\
\hline Clouds, rain and snow & 54 & 56 & 2 & 0.31 & 55 & 54 & -1 & -0.52 \\
\hline What is the rainbow/ why you see it. & 56 & 77 & 21 & 2.76 & 52 & 63 & 11 & 1.62 \\
\hline Weather and forecast & 78 & 87 & 9 & 1.03 & 56 & 58 & 2 & 0.95 \\
\hline $\begin{array}{l}\begin{array}{l}\text { Mountains, rivers and oceans and } \\
\text { develop }\end{array} \\
\end{array}$ & 50 & 46 & -4 & 0.21 & 53 & 57 & 4 & 0.31 \\
\hline Why the sky is blue/stars twinkle & 63 & 90 & 27 & 4.65 & 57 & 54 & -3 & -0.66 \\
\hline
\end{tabular}




\begin{tabular}{|c|c|c|c|c|c|c|c|c|}
\hline \multirow{2}{*}{$\begin{array}{l}\text { Things to learn } \\
\text { The greenhouse effect } \\
\end{array}$} & \multicolumn{4}{|c|}{ Experimental group } & \multicolumn{4}{|c|}{ Control group } \\
\hline & 66 & 88 & 22 & 2.79 & 45 & 50 & 5 & 0.98 \\
\hline The ozone layer & 63 & 71 & 8 & 1.1 & 64 & 67 & 3 & 0.23 \\
\hline The moon, the stars and planets & 66 & 89 & 23 & 3.98 & 67 & 68 & 1 & 0.76 \\
\hline Universe/stars constellations & 59 & 67 & 8 & 1.12 & 63 & 64 & 1 & 0.88 \\
\hline Rockets and spare travel & 73 & 88 & 15 & 3.09 & 67 & 68 & 1 & 0.69 \\
\hline Possibility of life outside earth. & 76 & 89 & 13 & 3.05 & 58 & 59 & 1 & 0.98 \\
\hline Electricity, produced and used at home. & 67 & 87 & 20 & 3.35 & 56 & 61 & 5 & 0.45 \\
\hline New sources of energy (sun wind) & 85 & 93 & 8 & 0.32 & 87 & 77 & -10 & -0.66 \\
\hline How telephone, radio, TV work. & 76 & 87 & 11 & 1.45 & 66 & 69 & 3 & 0.99 \\
\hline Computers and what are they for & 65 & 67 & 2 & 0.42 & 54 & 51 & -3 & -2.87 \\
\hline Latest developments in technology & 53 & 54 & 1 & 0.32 & 56 & 50 & -6 & -0.99 \\
\hline Satellites and modern communications & 65 & 67 & 2 & 1.23 & 66 & 67 & 1 & 0.14 \\
\hline S\&T towards better life. & 70 & 73 & 3 & 0.53 & 65 & 69 & 4 & 0.98 \\
\hline Possible dangers of S\&T. & 53 & 54 & 1 & 0.41 & 65 & 66 & 1 & 1.53 \\
\hline Plants we can eat and harvest & 83 & 93 & 10 & 1.78 & 76 & 79 & 3 & 1.33 \\
\hline Food processing/ conservation/ storage. & 78 & 81 & 3 & 0.66 & 56 & 59 & 3 & 1.23 \\
\hline Poisonous plants and mushrooms & 79 & 83 & 4 & 0.46 & 78 & 79 & 1 & 1.405 \\
\hline Improving harvest in gardens and farms & 71 & 72 & 1 & 0.34 & 67 & 68 & 1 & 1.62 \\
\hline How to get clean/safe drinking water. & 66 & 79 & 13 & 2.94 & 74 & 79 & 5 & 1.55 \\
\hline How to protect environment. & 84 & 89 & 5 & 0.52 & 76 & 80 & 4 & 2.43 \\
\hline X-rays and ultra sound machines & 68 & 86 & 18 & 3.01 & 76 & 82 & 6 & 1.98 \\
\hline Test-tube babies & 85 & 87 & 2 & 1.23 & 80 & 77 & -3 & -0.54 \\
\hline Birth control and contraceptives & 68 & 70 & 2 & 0.34 & 65 & 66 & 1 & 0.23 \\
\hline Children in other parts of the world & 77 & 89 & 12 & 2.98 & 87 & 88 & 1 & 0.45 \\
\hline How people look in different regions. & 72 & 73 & 1 & 0.32 & 70 & 69 & -1 & -0.45 \\
\hline S\&T to help the disabled & 43 & 50 & 7 & 0.53 & 47 & 49 & 2 & 1.06 \\
\hline How scientists think and work & 77 & 90 & 13 & 2.79 & 80 & 75 & -5 & -1.26 \\
\hline Famous scientists and their lives & 77 & 91 & 14 & 2.88 & 66 & 63 & -3 & -0.34 \\
\hline Important inventions and discoveries & 77 & 92 & 15 & 2.97 & 78 & 75 & -3 & -1.93 \\
\hline How nuclear power plant functions. & 56 & 77 & 21 & 3.24 & 44 & 63 & 19 & 2.78 \\
\hline What an atomic bomb consist of & 66 & 93 & 27 & 3.64 & 76 & 79 & 3 & 2.76 \\
\hline
\end{tabular}

Unedited double-journal entries (Day 1)

1. What questions do I have about today's activity?

a. Why did this happen?

b. How big can be bubble be blown?

c. Why does bubble form by blowing air in straw?

d. How can we make a large bubble?

e. Why does bubble burst when excess air is blown in?

$f$. Why does the bubble take a spherical shape always?
2. Something I have learned today

a. Steps of science experiments

b. There are many variables for an experiment

c. Rules to be followed to carry out activity

d. Predicting the result of activity

\section{Some thought-stimulating incident in class Today}

a. Modifying the set up to conduct the experiment by controlling appropriate variable 
b. To fix a problem while conducting the experiment requires thought process.

c. We all need to work together to get the results.

d.Proper observation is must to get correct conclusion.

The question about why does a bubble burst when over inflated and further the question regarding spherical shape of bubble shows the aspect of inquiry in the mind of student. This has to be catered by conducting some sought of guided discussion at the end of the session. As the class progressed for the experimental group through performing of activities and reflections towards the end, there was a sense of boldness in the answer to the questions in reflective $\log$. The unedited reflective $\log$ of the children for the activity conducted on day 12 is given as under.

\section{Unedited double-journal entries (Day 12)}

1. What questions do I have about today's activity?

a. Suppose we paint one jar black and the other white. In which will the water get hotter in sunshine?

b. Suppose we color the water black and white instead of the jars. Which colored water sample will get warmer in sunshine?

c. Suppose we leave the top off of one jar. What difference do we think there will be in the water temperatures after 15 minutes of sun?

d. Suppose we turn a capped jar upside down. What difference do we think there will be in the water temperature after 15 minutes of sun?

\section{Something I have learned today}

a. Conditions that affect how fast water absorbs the sun energy

b. Measurement of the temperature differences in several pairs of water samples

c. How to measure temperature accurately with thermometer

\section{Some thought-stimulating incident in class}

\section{Today}

a.I should be careful in accurate measurement of temperatures. Even slight error could affect my results.

b. Absorbed sunlight changes into heat energy; sunlight may be absorbed and trapped in several ways.

c. Comparison of temperature differences in the paired water samples with our fingers.

Unedited double-journal entries (Day 10)

1. What questions do I have about today's activity?

a) Does the amount of stretch in rubber band that is force depend on heights of different books?

b) If we find the stretch in rubber band for heights of one, two, three, five and six books, can we predict the stretch for four and seven books? c) If we switch the inclined plane with twice as long, what would be the result?

d) What are the different inclined planes we see in school?

\section{Something I have learned today}

a) Changing board lengths affect the force needed to go up a given height.

b) Doubling the length of an inclined board halves the force needed to go up a given height.

c) The force needed to go up an inclined plane increases with height and decreases with distance

\section{Some thought-stimulating incident in class}

\section{Today}

Two kinds of prediction can occur in investigation, one can predict within the data (interpolating), predict beyond the data (extrapolating).

\section{Unedited double-journal entries (Day 11)}

1. What questions do I have about today's activity?

a) Which liquid-water, soapy water, or alcohol has the largest drops, smallest drops

b) What kinds of droop prints do different liquid makes on newspaper?

c) What are the other liquids can be tested

d) How can drop sizes be compared?

\section{Something I have learned today}

a) Observation and comparison of the relative sizes of the drops of water, soapy water and alcohol

b) Predicting the relative size of drops of the two liquids after first observing how much each bulges in the field container

\section{Some thought-stimulating incident in class}

Today

a) Some liquids seems to stick together more strongly than others

b) Any liquid has the property of cohesion, the tendency of its molecules to stick together

c) Different liquids have different drop prints made on newspaper

Reflection helps students improve their basic communications skills both orally and in written form. It assists each student in self-examining his or her learning experience and leads to the development of better critical-thinking skills [19]. From the reflective $\log$ it can be seen that as the progress of instructional programme takes place the pupils becomes more and more proficient in the process of inquiry.

There is an improvement in skills especially Science Process Skills involving observation, prediction, inferring, hypothesizing, identifying variables, experimentation, measuring and communicating during the process of carrying out the activities and writing the reflective log. A steep change in their thinking process can be seen by the answers of the reflective log. During the day 1 of the 
activity the students of the experimental grp were not clear about the quest for which solution to be sought. As the days passed on there is clarity in the thinking process. The clarity and specificity of the answers to the reflective $\log$ for the activity no 12 is evidence of improvement in their skills and the approach of thinking.

During the intervention phase, while carrying out the activates the children of the experimental group were actively involved in performing various acts like observing readings, lifting things, measuring data, comparing information etc. which very much imitate the act of a scientist and it mends their interest in a creative direction. This shaped interest among the students to do something to bring out the scientist in them and arouse inclination towards the content taught. When students' personal meanings and connections to prior knowledge are limited, they have difficulty engaging in creative behaviours and rely on entrenched thoughts and extrinsic motivation [24]. The value that students place on subject matter or their interest in what they learn is a force that drives intrinsic motivation [25]. This motivation comes from the pleasure one gets from the task itself or from the sense of satisfaction in completing or even working on a task. Intrinsic motivation has been shown to yield greater success than external rewards. In addition, Schiefele and Csikszentmihalyi found that interest is related to both quality of experience during instruction as well as achievement. While analysing the reflections it was found that students were utilizing different process skills and were going through the path of exploring beginning with observation, variable identification, predicting, inferring, communicating, hypotheses framing and ultimately reaching the target through the cycle of experience and reflection. Through this process the students were able to reflect and evaluate their own learning process and improve upon that. This could ultimately bring about positive impact in their achievement.

Research shows that students' affective states contribute to their achievement. To be successful, students must find instruction motivating and meaningful (Caine \& Caine [24], Schiefele and Csikszentmihalyi [25], Tomlinson, [26]). Varying instruction based on what students want to know and how they prefer to learn helps to create a collaborative, learner-centred climate that has positive effects on students' achievement. Such a practice requires that students be given opportunities to engage in hands-on, open-ended activities and provided with time and resources to explore their interests [27]. Learning by doing is the watchword towards inculcation of experiential learning among students. Teachers should seek out information related to their students' interests and backgrounds and adopt a role as facilitator, turning more responsibility for learning over to students.

\section{References}

[1] National Curriculum Framework, 2005, pp. (17-18). Retrieved from ncf2005.wordpress.com/chapter-wisesummary (Access Date: 8 June, 2010).

[2] Piaget, J. (1970). Piaget's theory. In P.H. Mussen (Ed.) Carmichael's manual of child psychology. (3rd ed.), pp. (703-732). New York: Wiley.

[3] Bruner, J. (1960). A Process of Education: A Landmark in Educational Theory. USA: President and Fellows of Harvard College.

[4] Gray, J. (1978). The student success handbook for learners in project based Science environment. Proceedings of ICLS (International conference of the Learning Sciences): The University of Michigan, Ann Arbor, Michigan.

[5] Vygotsky, L.S. (1978). Mind in Society: The Development of Higher Psychological Processes. In Cole, M., John-Steiner,V., Scribner, S., \&Souberman, E. (Eds.). Massachusetts: Harvard University Press.

[6] Cranston, M. (1982) Jean-Jacques: The Early Life and Work. New York: Norton. Retrieved from http://www.jstor.org/stable/2124413?seq=1\#page_scan_tab _contents (Access Date: 1st June, 2015)

[7] Zemelman, S. and Hyde, A. and Daniels, H., (2005). Best Practice, Today's Standards for Teaching and Learning in America's Schools. Portsmouth: Heinemann, A division of Reed Elsevier Inc.

[8] Experiential Learning Defined, Learning Science, The University of Texas, Austin, 2015, Retrieved from https://learningsciences.utexas.edu/teaching/engagement/e xperiential-learning/defined (Access Date: 10th May, 2015).

[9] Kolb, D. A. (1984). Experiential Learning: Experience as the source of learning and development. Englewood Cliffs: Prentice- Hall. In Norbert M. Seel, Encyclopedia in the Sciences of Learning, Springer Science, London, 2012.

[10] Wurdinger, D. D., \& Carlson, J. A. (2010). Teaching for experiential learning: Five approaches that work. Lanham, MD: Rowman\& Littlefield Education. In Experiential Learning Defined,Learning Science, The University of Texas, Austin, 2015, Retrieved from https://learningsciences.utexas.edu/teaching/engagement/e xperiential-learning/defined (Access Date: 10th May, 2015).

[11] Marlow P., McLain, B., Assessing the impacts of experiential learning on teacher classroom practice, Research in Higher Education Journal, pp. 1-15, http://www.aabri.com/manuscripts/11919.pdf (Access Date: 1st June, 2015).

[12] Dale, Edgar. (1969). Audio-Visual Methods in Teaching, 3rd ed. New York: Holt, Rinehart \&Winston , p. 108 . 
[13] Cheriyan, V. K., Theoretical Overview, (2014). shodhganga.inflibnet.ac.in/bitstream/10603/22800/10/10_c hapter2.pdf, (Access Date: 1st June, 2015).

[14] James, T. (1980/2000). Can the Mountains Speak for Themselves? Scisco: Conscientia, 2(3), 1-17.

[15] Bacon, S. B. (1987). The evolution of the outward bound process. Greenwich, CT: Outward Bound USA.

[16] Neill, J.T. (2002). Are the mountains still speaking for themselves? A defining tension 20 years on.Unpublished Paper, University of NewHampshire, NH, USA. In Cheriyan, V. K., Theoretical Overview, (2014). Retrieved from shodhganga.inflibnet.ac.in/bitstream/10603/22800/10/10_c hapter2.pdf, (Access Date: 1st June, 2015).

[17] R. Baird, Peter J. Fensham, Richard F. Gunstone, and Richard T. White,(1991). The Importance of Reflection In Improving Science Teaching And Learning. Journal of Research in Science Teaching, 28(2), PP. 163-182.

[18] Halpern, D. F. Thought and Knowledge: An Introduction to Critical Thinking. (3rd ed.) Mahwah, N.J.: Erlbaum, 1996.

[19] J. McDonald, James; Dominguez, Lynn, (2009). Developing Patterns for Learning in Science through Reflection, The Science Teacher, Retrieved on 22nd Dec, 2015, from https://www.questia.com/library/journal/1G1197489022/reflective-writing-developing-patterns-forthinking

[20] National Research Council, (1996). National Science Education Standards. The National Academic Press, Paperback ISBN:978-0-309-05326-6

DOI: $10.17226 / 4962$

[21] Svein Sjoberg, Jayashree Mehta and Jane Mulemwa (2000). Science And Scientists: The SAS-study. Department of Teacher Education and School Development. Norway: University of Oslo.

[22] Sample reflection activities, Retrieved on 22nd Dec, 2015 from

http://www.pstcc.edu/service-

learning/_files/pdf/ReflectionActivities.pdf

[23]David Clark-Carter, (2009).Quantitative psychological Research: The Complete Student's Companion. New York, NY: Taylor \& Francis.

[24] Caine, G., \& Caine, R. N. (1997).Education on the edge of possibility. Alexandria, VA: Association for Supervision and Curriculum Development.

[25] Schiefele, U., and Csikszentmihalyi, (1995). Motivation and Ability as Factors in Mathematics Experience and Achievement.Journal for Research in Mathematics Education, 26(2), 163-181.

[26] Using Effective Instructional Strategies: InterestBased Learning, Ohio Dept. of Education, Retrieved from http://ims.ode.state.oh.us/ode/ims/rrt/research/Content/inte rest_based_learning_what_we_know.asp

(Access Date:10th June, 2015).

[27] Nath,S.(2015). Gauging Change in Preference about Students' Interest or What They Would Like To Learn: Development and Tryout of an Instructional Programme on Experiential Learning in Science Education. London: LICE Proceedings.

[28] Reflective thinking, John Dewey and PBL, retrieved on $22^{\text {nd }}$ Dec 2015 from

http://www.imsa.edu/ bernie/dewey.html

[29] Dewey, J. (1938) Experience and Education, New York: Collier Books.

[30] Hahn, K. (1957). Outward bound. New York City: World Books.

[31] Freire, P. (1970). Pedagogy of the oppressed (M. B. Ramos, Trans.). New York: Continuum. 